\title{
Thyroid Autoantibodies in Egyptian Patients with Autoimmune Rheumatic Diseases: Relation to Disease Activity and Functional Impairment Safaa Abd Elsalam Hussein ${ }^{1}$, Howaida Elsayed Mansour ${ }^{1}$, Mohammed Salah Hussein ${ }^{2}$, Ayat Sami Mohamed Abdel Aziz ${ }^{1}$, Nermeen Noshy Aziz ${ }^{1}$ \\ ${ }^{1}$ Department of Internal Medicine, Division of Rheumatology, Faculty of Medicine, Ain Shams University, ${ }^{2}$ Department of Internal Medicine, Faculty of Medicine, Al-Azhar University, Cairo, Egypt \\ *Corresponding author: Safaa Abd Elsalam Hussein, email: safaa.abdelsalam@gmail.com
}

\begin{abstract}
Background: Autoantibodies against the thyroid seem to be more common in patients with rheumatic diseases than in the normal population. Their appearance may be linked to an associated autoimmune thyroid disease. Knowing the degree of association between rheumatic and thyroid diseases may help the clinician to make the correct decision.

Objectives: The aim of the work was to estimate the prevalence of thyroid autoantibodies among patients with systemic autoimmune rheumatic diseases with or without thyroid disorders and its association with disease activity and functional impairment.

Patients and Methods: The current study included 60 patients and 20 healthy controls. Patients were divided into three groups; systemic lupus erythematosus (SLE), rheumatoid arthritis (RA) and systemic sclerosis (SSc). Clinical and laboratory assessment were done to all patients including routine laboratory investigations and thyroid function tests (thyroid stimulating hormone [TSH], T3 and T4), and thyroid autoantibodies; antithyroglobulin (TgAb) and anti-thyroperoxidase (TPOAb).

Results: SLE group had significant $(\mathrm{P}=0.018)$ lower age than other groups. Antithyroid antibodies and thyroid disorders were more common in SSc and SLE patients than RA patients and control subjects; however, no significant difference between studied groups. Presence of autoantibodies with and without thyroid disorders was not associated with the activity or functional indexes evaluated.

Conclusion: The prevalence of thyroid autoantibodies in SLE and SSc patients was higher than in RA patients. No link could be established between the presence of thyroid autoantibodies and the results from any of the instruments used to measure inflammatory activity and functional impairment in these cases of rheumatic diseases.
\end{abstract}

Keywords: Thyroid autoantibodies, Autoimmunity, Rheumatic disease, RA, SLE, SSc

\section{INTRODUCTION}

Autoimmune thyroid disease (AITD) is a term used to describe a group of pathologies that has thyroid dysfunction, and an autoimmune response against this endocrine organ as its hallmark (1). However, being a group of autoimmune diseases (ADs) clustered together, the clinical presentation varies among these diseases; it can be divided into those that cause hypothyroidism, hyperthyroidism, or both ${ }^{(2)}$. The major antigens of thyroid autoantibodies are thyroglobulin (Tg), thyroid peroxidase (TPO) and thyroid-stimulating hormone receptor (TSH-R) ${ }^{(3)}$. Hypothyroidism and rheumatic diseases share common clinical findings such as arthralgias, arthritis, myalgias, myopathy and fatigue, which need to be correctly diagnosed to be properly treated. Knowing the degree of association between rheumatic and thyroid diseases may help the clinician to make the correct decision ${ }^{(4)}$.

Rheumatoid arthritis is a systemic disease characterized by inflammatory peripheral arthritis. An association between AITDs with or without thyroid dysfunction and RA has been reported in adults; however, the pathogenic mechanism remains uncertain ${ }^{(5)}$. SLE is an autoimmune disease that affects the skin, kidneys, musculoskeletal, hematologic systems, and it is characterized by the presence of various autoantibodies against selfcomponents, especially double-stranded deoxyribonucleic acid and ribonucleic acid-binding nuclear proteins. Thyroid autoantibodies have been found more often in patients with SLE than in the general population and even in patients with no thyroid disease ${ }^{\left({ }^{(}\right)}$. Progressive systemic sclerosis $(\mathrm{SSc})$ is a connective tissue disease, characterized by vascular abnormalities, multiorgan fibrosis and complex immune system alterations. The association of $\mathrm{SSc}$ with thyroid fibrosis, hypothyroidism and thyroid autoimmunity has been reported by several studies in a wide range of variability ${ }^{(7)}$.

The aim of the current study was to estimate the prevalence of thyroid autoantibodies among patients with systemic rheumatic disease (SLE, RA and SSc) with or without thyroid 
disorders and its association with disease activity and functional impairment.

\section{PATIENTS AND METHODS}

This case control observational study included a total of sixty patients with rheumatic diseases and twenty healthy controls, recruited from Rheumatology Department and Out-patients' Clinic, Ain Shams University Hospital.

\section{Ethical approval:}

The study was approved by the Ethical Committee of Ain Shams University and written informed consent was obtained from subjects.

The included 60 rheumatic disease patients were divided into three groups; Group 1 systemic lupus erythematosus; (SLE), Group 2 rheumatoid arthritis; (RA) and group 3 systemic sclerosis; (SSc), each consisted of 20 patients.

Clinical and laboratory assessment were done to all patients and controls including thyroid function tests (TSH, T3 and T4), and thyroid autoantibodies; anti-thyroglobulin ( $\mathrm{TgAb}$ ) and anti-thyroperoxidase (TPOab). SLE patients diagnosed by 2019 European League Against Rheumatism/American College of Rheumatology (EULAR/ACR) classification criteria for SLE which requires a positive ANA as obligatory entry criterion. Patients accumulating $\geq 10$ points are classified as having lupus ${ }^{(8)}$. RA patients needed to have six points or more of the 2010 classification criteria from the ACR/EULAR ${ }^{(9)}$. SSc patients needed to achieve at least nine points in the 2013 ACR/EULAR classification criteria ${ }^{(7)}$.

Clinical evaluation was done including full history taking with emphasis on symptoms of disease activity, organ damage and medications. Disease activity assessment for SLE patients was performed using the SLE Disease Activity Index (SLEDAI) ${ }^{(10)}$ and damage assessment was done using the Systemic Lupus International Collaborating Clinics/American College of Rheumatology damage index (SLICC/ACR) ${ }^{(11)}$. Disease activity assessment for RA patients was performed using the Disease Activity Score-28 using the erythrocyte sedimentation rate (DAS28ESR) ${ }^{(12)}$ and the Health Assessment Questionnaire (HAQ) was done to quantify physical disability and the corresponding functional status ${ }^{(13)}$. For SSc patients; the Rodnan modified index (Rodnan-m) was measured to evaluate the degree of skin involvement ${ }^{(14)}$, and the Medsger index to evaluate the degree of systemic involvement ${ }^{(15)}$.

Routine Laboratory investigations were done including complete blood picture using coulter JS and cell counter, erythrocyte sedimentation rate (ESR) by Westergren method, C-reactive protein with titer by immunoturbidimetric method, liver enzymes; aspartate aminotransferase (AST) and alanine aminotransferase (ALT), kidney function tests; creatinine and blood urea nitrogen (BUN) by calorimetric method and complete urine analysis. Protein/ creatinine ratio in morning sample was estimated to evaluate proteinuria in SLE patients. Serum complement 3 and 4 were measured for SLE patients. Echocardiography, pulmonary function tests (PFT) and lung diffusion capacity (DLCO) for SSc patients. Thyroid profile; (TSH, T3 and T4), thyroid autoantibodies; anti-thyroglobulin antibody $(\mathrm{Tg} \mathrm{Ab})$ and anti-thyroperoxidase antibody (TPOAb) were done.

\section{Statistical analysis}

The collected data were coded, tabulated, and statistically analyzed using SPSS program (Statistical Package for Social Sciences) software version 23.0. Description of quantitative variables as mean, standard deviation (SD) and range. Description of qualitative variables as number (no) and percentage (\%). Chi-square test was used to compare qualitative variables. One Way ANOVA test and Kruskal Wallis test were used instead of Chi-square test when one expected cell or more $\leq$ 5. Independent t-test and Mann Whitney test were also used. Unpaired t-test was used to compare two independent groups as regard quantitative variables. P-value $\leq 0.05$ was considered significant.

\section{RESULTS}

Sixty patients and 20 healthy controls were studied. The mean age for SLE patients was $34.25 \pm 7.22$ years $(22-46), 18$ patients were females. The median for SLEDAI was $9.00(0-20)$, and SLICC/ACR-DI was 1 (0-3). Thyroid antibodies (TgAbs \& TPO Abs) were positive in 5 (25\%) SLE patients. The mean age for RA patients was $42.20 \pm 9.63$ years (26-66), all of them were females. The mean DAS score was 4.4 \pm 1.19 (3.03$6.42)$. Thyroid antibodies were positive in $2(10 \%)$ RA patients. The mean age for SSc patients was $40.60 \pm 9.09$ years $(22-56)$, all of them were females. The mean Rodnan-m score was $13.2 \pm 6.83$ (4-26), and Medsger index mean score was $1.65 \pm 0.67$ (1-3). As regards PFTs in SSC, 4 patients (20\%) had normal PFTs while 16 patients $(80 \%)$ had restrictive PFTs. In SSc patients the mean DLCO was $78.10 \pm 7.89 \%(65-90 \%)$ and the mean ejection fraction $(\mathrm{EF})$ was $60.5 \pm 6.42 \%$ (45$69 \%)$. Thyroid antibodies were positive in $6(30 \%)$ SSc patients. The mean age for the control subjects was $35.80 \pm 9.83$ years (25-63), 12 patients were 
females. Thyroid antibodies were positive in 3 $(15 \%)$ subjects of the control group (Table 1). The prevalence of thyroid disorders (hypothyroidism and hyperthyroidism) in our study was (30\%) in SLE patients, (5\%) in RA patients, (25\%) in SSc patients and (20\%) in control group.

In the present study there was a significant difference $(\mathrm{P}=0.018)$ between studied groups as regard age; SLE group had lower age than other groups, high significant difference between studied groups as regard sex, while, no significant difference between studied groups as regard smoking (Table 2). There was no significant difference between studied groups as regard thyroid function tests (TSH, T3 and T4) (Table 3). There were more antithyroid antibodies (Tg Abs \&
TPO Abs) in SSc and SLE groups; however, there was no significant difference between studied groups as regard ATA (Table 4). There was no significant difference $(\mathrm{p}=0.184)$ between studied groups as regard the presence or absence of thyroid diseases; however, they were more common in SSc and SLE patients (Table 5).

There was no significant difference between SLE patients with and without positive thyroid Abs as regard SLEDAI score and SLICC/ACR damage index (Table 6), the same was for SSc patients as regard Rodnan modified index and Medsger index (Table 7). Also, there was no significant difference between RA patients with and without positive thyroid Abs as regard DAS-28 ESR \& HAQ scores (Table 8).

Table (1): Prevalence of thyroid diseases and antithyroid antibodies (ATA) in rheumatic disease patients \& control group.

\begin{tabular}{|l|c|c|c|c|}
\hline & RA group & SLE group & SSC group & Control group \\
\hline Hypothyroidism & 1 & 5 & 3 & 3 \\
\hline Hyperthyroidism & - & 1 & 2 & 1 \\
\hline Anti Tg \& Anti TPO & 2 & 5 & 6 & 3 \\
\hline $\begin{array}{l}\text { Anti Tg \& Anti TPO with } \\
\text { thyroid disease }\end{array}$ & 0 & 1 & 1 & 0 \\
\hline $\begin{array}{l}\text { Anti Tg \& Anti TPO without } \\
\text { thyroid disease }\end{array}$ & 2 & 4 & 5 & 3 \\
\hline
\end{tabular}

Table (2): Comparison between studied groups as regard demographic data.

\begin{tabular}{|c|c|c|c|c|c|c|c|c|}
\hline & $\begin{array}{c}\text { Control } \\
\text { group }\end{array}$ & SLE group & RA group & SSC group & \multirow{2}{*}{$\begin{array}{c}\text { Test } \\
\text { value }\end{array}$} & \multirow{2}{*}{$\begin{array}{c}P \text { - } \\
\text { value }\end{array}$} & \multirow[t]{2}{*}{ Sig. } \\
\hline & & No. $=20$ & No. $=20$ & No. $=20$ & No. $=20$ & & & \\
\hline Age (years) & $\begin{array}{l}\text { Mean } \\
\pm \text { SD }\end{array}$ & $35.80 \pm 9.83$ & $34.25 \pm 7.22$ & $42.20 \pm 9.63$ & $40.60 \pm 9.09$ & $3.547 \bullet$ & 0.018 & S \\
\hline Sex & $\begin{array}{l}\text { Male } \\
\text { Female }\end{array}$ & $\begin{array}{c}8(40.0 \%) \\
12(60.0 \%)\end{array}$ & $\begin{array}{c}2(10.0 \%) \\
18(90.0 \%)\end{array}$ & $\begin{array}{c}0(0.0 \%) \\
20(100.0 \%)\end{array}$ & $\begin{array}{c}0(0.0 \%) \\
20(100.0 \%)\end{array}$ & $19.657 *$ & 0.000 & HS \\
\hline Smoking & $\begin{array}{l}\text { Yes } \\
\text { No }\end{array}$ & $\begin{array}{c}3(15.0 \%) \\
17(85.0 \%)\end{array}$ & $\begin{array}{c}1(5.0 \%) \\
19(95.0 \%)\end{array}$ & $\begin{array}{c}0(0.0 \%) \\
20(100.0 \%)\end{array}$ & $\begin{array}{c}0(0.0 \%) \\
20(100.0 \%)\end{array}$ & $6.316^{*}$ & 0.097 & NS \\
\hline
\end{tabular}

P-value >0.05: Non-significant (NS); P-value <0.05: Significant (S); P-value <0.01: highly significant (HS); *: Chi-square test; $\bullet:$ One Way ANOVA test

Table (3): Comparison between studied groups as regard thyroid function tests.

\begin{tabular}{|c|c|c|c|c|c|c|c|c|}
\hline & $\begin{array}{c}\text { Control } \\
\text { group }\end{array}$ & SLE group & RA group & SSC group & \multirow{2}{*}{$\begin{array}{c}\text { Test } \\
\text { value }\end{array}$} & \multirow{2}{*}{$\begin{array}{c}\text { P- } \\
\text { value }\end{array}$} & \multirow[t]{2}{*}{ Sig. } \\
\hline & & No. $=20$ & No. $=20$ & No. $=20$ & No. $=20$ & & & \\
\hline $\begin{array}{l}\text { TSH } \\
(\mathrm{mU} / \mathrm{L})\end{array}$ & Median (IQR) & $\begin{array}{c}2.37 \\
(1.91-2.86)\end{array}$ & $\begin{array}{c}2.26 \\
(1.4-3.28)\end{array}$ & $\begin{array}{c}2.04 \\
(1.56-2.82)\end{array}$ & $\begin{array}{c}2.53 \\
(1.87-3.4)\end{array}$ & $1.071 \neq$ & 0.784 & NS \\
\hline $\begin{array}{l}\mathrm{T} 3 \\
\text { (ng/dL) }\end{array}$ & Mean \pm SD & $2.66 \pm 0.61$ & $2.67 \pm 0.72$ & $2.61 \pm 0.50$ & $2.98 \pm 0.02$ & $0.436^{\bullet}$ & 0.728 & NS \\
\hline T4 (ng/dL) & Mean \pm SD & $1.28 \pm 0.29$ & $1.23 \pm 0.24$ & $1.18 \pm 0.21$ & $1.66 \pm 0.26$ & $2.099 \bullet$ & 0.107 & NS \\
\hline
\end{tabular}

P-value $>0.05$ : Non-significant (NS); P-value <0.05: Significant (S); P-value $<0.01$ : highly significant (HS); $\bullet$ One

Way ANOVA test; + : Kruskal Wallis test 
Table (4): Comparison between studied groups as regard $\mathrm{Tg} \mathrm{Ab}$ and $\mathrm{TPO} \mathrm{Ab}$.

\begin{tabular}{|c|c|c|c|c|c|c|c|c|c|c|c|c|}
\hline & \multicolumn{2}{|c|}{ Control group } & \multicolumn{2}{|c|}{ SLE group } & \multicolumn{2}{|c|}{ RA group } & \multicolumn{2}{|c|}{ SSC group } & \multirow{2}{*}{$\begin{array}{l}\text { Test } \\
\text { value* }\end{array}$} & \multirow{2}{*}{$\begin{array}{c}\text { P- } \\
\text { value }\end{array}$} & \multirow{2}{*}{ Sig. } \\
\hline & & \begin{tabular}{|l} 
No. \\
.
\end{tabular} & $\%$ & No. & $\%$ & No. & $\%$ & No. & $\%$ & & & \\
\hline \multirow{2}{*}{$\mathrm{Tg} \mathrm{Ab}$} & Positive & 3 & $15.0 \%$ & 5 & $25.0 \%$ & 2 & $10.0 \%$ & 6 & $30.0 \%$ & \multirow{2}{*}{3.125} & \multirow{2}{*}{0.373} & \multirow{2}{*}{ NS } \\
\hline & Negative & 17 & $85.0 \%$ & 15 & $75.0 \%$ & 18 & $90.0 \%$ & 14 & $70.0 \%$ & & & \\
\hline \multirow{2}{*}{ TPO Ab } & Positive & 3 & $15.0 \%$ & 5 & $25.0 \%$ & 2 & $10.0 \%$ & 6 & $30.0 \%$ & \multirow{2}{*}{3.125} & \multirow{2}{*}{0.373} & \multirow{2}{*}{ NS } \\
\hline & Negative & 17 & $85.0 \%$ & 15 & $75.0 \%$ & 18 & $90.0 \%$ & 14 & $70.0 \%$ & & & \\
\hline
\end{tabular}

P-value >0.05: Non-significant (NS); P-value <0.05: Significant (S); P-value< 0.01: highly significant (HS); *: Chi-

square test

Table (5): Comparison between studied groups as regard presence or absence of thyroid diseases.

\begin{tabular}{|c|c|c|c|c|c|c|c|c|c|c|c|}
\hline \multirow{2}{*}{ Thyroid } & \multicolumn{2}{|c|}{ Control group } & \multicolumn{2}{|c|}{ SLE group } & \multicolumn{2}{|c|}{ RA group } & \multicolumn{2}{|c|}{ SSC group } & \multirow{2}{*}{$\begin{array}{c}\text { Test } \\
\text { value* }^{*}\end{array}$} & \multirow{2}{*}{$\begin{array}{c}\text { P- } \\
\text { value }\end{array}$} & \multirow{2}{*}{ Sig. } \\
\hline & No. & $\%$ & No. & $\%$ & No. & $\%$ & No. & $\%$ & & & \\
\hline $\begin{array}{l}\text { With } \\
\text { Without }\end{array}$ & $\begin{array}{c}3 \\
17\end{array}$ & $\begin{array}{l}15.0 \% \\
85.0 \%\end{array}$ & $\begin{array}{c}6 \\
14\end{array}$ & $\begin{array}{l}30.0 \% \\
70.0 \%\end{array}$ & $\begin{array}{c}1 \\
19\end{array}$ & $\begin{array}{c}5.0 \% \\
95.0 \%\end{array}$ & $\begin{array}{c}5 \\
15\end{array}$ & $\begin{array}{l}25.0 \% \\
75.0 \%\end{array}$ & 4.841 & 0.184 & \\
\hline
\end{tabular}

P-value $>0.05$ : Non-significant (NS); P-value $<0.05$ : Significant (S); P-value $<0.01$ : highly significant (HS);

*: Chi-square test

Table (6): Comparison between SLE group with positive thyroid Abs \& with negative thyroid Abs as regard disease activity measured by SLEDAI score and SLICC/ACR damage index.

\begin{tabular}{|c|c|c|c|c|c|c|c|c|}
\hline & \multicolumn{4}{|c|}{ Tg Ab \& or TPo } & \multirow{3}{*}{$\begin{array}{c}\text { Test } \\
\text { value* }^{*}\end{array}$} & \multirow{3}{*}{$\begin{array}{c}P \text { - } \\
\text { value }\end{array}$} & \multirow{3}{*}{ Sig. } \\
\hline & & \multicolumn{2}{|c|}{ Positive } & \multicolumn{2}{|c|}{ Negative } & & & \\
\hline & & No. $=5$ & $25 \%$ & $\begin{array}{c}\text { No. }= \\
15\end{array}$ & $75 \%$ & & & \\
\hline SLEDAI & Median (IQR) & \multicolumn{2}{|c|}{$14(7-16)$} & \multicolumn{2}{|c|}{$8(4-14)$} & $0.833^{\neq}$ & 0.405 & NS \\
\hline SLICC/ACR & Median (IQR) & \multicolumn{2}{|c|}{$1(0-3)$} & \multicolumn{2}{|c|}{$1.0(0-2)$} & $0.548^{\neq}$ & 0.584 & NS \\
\hline
\end{tabular}

$\neq$ : Mann-Whitney test

Table (7): Comparison between SSC group with positive thyroid Abs \& with negative thyroid Abs as regard Rodnan modified index and Medsger index.

\begin{tabular}{|l|l|c|c|c|c|c|}
\hline \multicolumn{2}{|c|}{} & \multicolumn{2}{|c|}{ Tg Ab \& or TPo } & \multirow{2}{*}{$\begin{array}{c}\text { Test } \\
\text { value• }\end{array}$} & $\begin{array}{c}\text { P- } \\
\text { value }\end{array}$ & \multirow{2}{*}{ Sig. } \\
\cline { 3 - 5 } & Positive & Negative & No. = 6 & No. $=14$ & 14 & \\
\hline Rodnan modified index & Mean \pm SD & $12.67 \pm 3.58$ & $13.43 \pm 3.77$ & -0.223 & 0.826 & NS \\
\hline Medsger index & Mean \pm SD & $1.67 \pm 0.82$ & $1.64 \pm 0.63$ & 0.071 & 0.944 & NS \\
\hline
\end{tabular}

$\because$ Independent t-test

Table (8): Comparison between RA group with positive thyroid Abs \& with negative thyroid Abs as regard DAS 28 \& HAQ score.

\begin{tabular}{|l|c|c|c|c|c|c|}
\hline \multicolumn{2}{|c|}{} & \multicolumn{2}{|c|}{ Tg Ab\& or TPo } & \multirow{2}{*}{$\begin{array}{c}\text { Test } \\
\text { value• }\end{array}$} & \multirow{2}{*}{$\begin{array}{c}\text { P- } \\
\text { Value }\end{array}$} & \multirow{2}{*}{ Sig. } \\
\cline { 3 - 6 } \multicolumn{2}{|c|}{} & Positive & Negative & No.18 & & \\
\cline { 3 - 7 } & No.2 & $4.30 \pm 1.19$ & 1.153 & 0.264 & NS \\
\hline DAS 28 & Mean \pm SD & $5.31 \pm 1.06$ & $1.67 \pm 0.77$ & 0.600 & 0.556 & NS \\
\hline
\end{tabular}

$\because$ Independent t-test

\section{DISCUSSION}

Clustering of specific autoimmune diseases such as thyroiditis and systemic autoimmune diseases such as rheumatic diseases in the same patient is commonly noted, although the reasons for these associations are not completely clear. A common genetic background is one of the proposed explanations for this link. Another explanation that has been put forward is that there may have been an exposure to a common triggering event such as a pollutant or a viral infection. In this regard, infections due to the Epstein-Barr virus and tobacco exposure have been implicated in both situations ${ }^{(16)}$. 
In the present study, we aimed to estimate the prevalence of thyroid autoantibodies among patients with systemic rheumatic diseases (SLE, RA and SSc) with or without clinical thyroid disorders and its association with disease activity and functional impairment.

In the current study, we found that $90 \%$ of SLE recruited patients were females, $100 \%$ of RA $\&$ SSc patients were females and it was $60 \%$ in the control group. This agrees with Posselt et al. ${ }^{(16)}$, who evaluated the prevalence of thyroid autoantibodies in patients with systemic autoimmune rheumatic diseases and found that female gender in SLE patients was $93.6 \%$, in RA patients was $90.9 \%$, in SSc patients was $94.8 \%$ and control group was $92.1 \%$. The previous findings confirm that female sex is predominant in RA, SLE and SSc patients.

In the current study, we found that SSc patients' mean age was $40.60 \pm 9.09$ years, versus $35.80 \pm 9.83$ years for control subjects. This agrees with Shahin et al. ${ }^{(17)}$, who evaluated prolactin and thyroid hormones in 23 systemic sclerosis patients; and found that their mean age was $37.7 \pm 12.7$ years versus $35.6 \pm 8.2$ years for 15 normal control subjects.

In the current study, we found that the mean serum level of FT4 in SSc patients was $1.66 \pm 1.26 \mathrm{ng} / \mathrm{dl}$ and in control group $1.28 \pm 0.29$ $\mathrm{ng} / \mathrm{dl}$. That was different from Shahin et al. ${ }^{(17)}$, who found that mean serum levels of FT4 in SSc patients was $7.46 \pm 2.7 \mathrm{pmol} / \mathrm{L}$ (equal to 0.579 $\mathrm{ng} / \mathrm{dl}$ ) and in controls was $10.47 \pm 2.5 \mathrm{pmol} / \mathrm{L}$ (equal to $0.813 \mathrm{ng} / \mathrm{dl}$ ). These variations might be due other co-morbidities in their patients.

Thyroid dysfunction is common in SLE and RA. Many are initially treated for thyroid dysfunction before the diagnosis of lupus or rheumatoid is made or vice versa ${ }^{(18)}$. The prevalence of thyroid disorders (hypothyroidism and hyperthyroidism) in our study was 30\% in SLE patients, 5\% in RA patients, $25 \%$ in SSc patients and $20 \%$ in control group. So, prevalence of thyroid disorders in SLE and SSc patients were more than that of RA, however, there was no statistically significant difference between studied groups as regard presence or absence of thyroid diseases. On the other hand, Lin et al. ${ }^{(19)}$ reported that the prevalence of thyroid disease was $8.1 \%$ \& $16.9 \%$ in SLE patients and controls respectively, while Appenzeller et al. ${ }^{(20)}$ found that thyroid disease (predominantly hypothyroidism) was observed in $6.1 \%$ and $2 \%$ in SLE patients and controls respectively. The variations between the previous two studies and our study might be due to different sample sizes and racial variations.
Our results were also variable from ElHadidi et al. ${ }^{(21)}$, who found that the prevalence of thyroid dysfunction was more among lupus patients than controls (18\% vs. $4 \%$ ), and also from El Sherif et al. ${ }^{(22)}$, who evaluated thyroid disorders and autoantibodies in SLE and RA patients and found that thyroid disorders (hypothyroidism and hyperthyroidism) were significantly more common in SLE patients (50\%) than in RA patients $(15 \%)$.

The prevalence of hypothyroidism in our study was (25\%), (5\%), (15\%) and (15\%) in SLE, RA, SSc patients and control group respectively. This was different from Watad et al. (23), who found that the proportion of hypothyroidism in SLE patients was $15.58 \%$ versus $5.75 \%$ in controls, and from Shahin et al. ${ }^{(17)}$, who found that hypothyroidism was $33.3 \%$ in 23 SSc patients. Also, Posselt et al. (16), who found that the prevalence of hypothyroidism was (16.2\%), (16.1\%), (27.5\%) and (11.3\%) in SLE, RA, SSc patients and control group respectively.

Regarding SLE, our findings were higher than Franco et al. ${ }^{(3)}$ and Mader et al. ${ }^{(24)}$, who found that the prevalence of hypothyroidism was $12 \%$ and $11.6 \%$ respectively in their cohort studies. The differences in these results could be explained by racial differences, region variations, patient selection (age and sex), size of sample, duration of follow up, influence of medications and diagnostic methods for the detection of thyroid disorders. Patients were on high-dose corticosteroids and other immunosuppressive drugs owing to their higher disease activity, indicating a possible role of these drugs on such type of thyroid dysfunctions.

In the current study, we have found that antithyroid antibodies (ATA) in SLE and SSc patients with or without thyroid disorders were higher than RA patients and healthy controls. ATA were positive in $25 \%$ of SLE patients, $30 \%$ of SSc patients and $10 \%$ of RA patients while were positive in $15 \%$ of control subjects. This agrees with Przygodzka and Filipowicz-Sosnowska ${ }^{(25)}$, who found that AbTg was positive in $12 \%$, AbTPO was positive in $15 \%$ of RA patients and AbTg was positive in 9\%, AbTPO was positive in 18\% of controls. Our results were near to Posselt et al. ${ }^{(16)}$, who reported that the prevalence of thyroid antibodies at least one antithyroid antibodies (ATA) was (32.8\%), (19.5\%), (36.2\%) \& (16.3\%) in SLE, RA, SSc patients and control group respectively.

In our study, it was found that SLE patients were positive for Tg antibodies \& TPO antibodies 1.6 times more than healthy controls. These findings were different from Pan et al. ${ }^{(26)}$, who found that their SLE patients were positive for $\mathrm{Tg}$ antibodies 2.9 times and TPO antibodies 2.2 times 
more than healthy controls. While our findings were quite near to Kumar et al. ${ }^{(27)}$, who found that the prevalence of Thyroid $\mathrm{Ab}$ was positive in $30 \%$ of 100 SLE patients and $10 \%$ of 100 controls.

An American cohort study was done by Pyne and Isenberg (28) to assess autoimmune thyroid disease in SLE; it was found that patients with thyroid disorders had higher prevalence of antithyroid antibodies (66\%) than patients with normal thyroid functions, confirming the coexistence of the SLE and ATD. In a study done by Shahin et al. ${ }^{(17)}$, who assessed AbTg in 45 SLE patients \& 20 controls; it was found that AbTg was positive in $18.5 \%$ of SLE patients \& $0 \%$ of controls. Another Latin American study done by Innocencio et al. ${ }^{(29)}$; it was found that anti-Tg and anti-TPO were positive in $52 \%$ of SSc and $3.5 \%$ of controls which confirms a high prevalence of thyroid autoantibodies in SSc. Another metaanalysis study done by Pan $\boldsymbol{e t}$ al. ${ }^{(26)}$; they found that thyroid Abs were positive in $95 \%$ of SLE patients \& 5\% of healthy controls. Our results agreed with a study done by Chan et $\mathbf{a l} .{ }^{(30)}$, who found that there was a higher prevalence of antiTPO Abs and anti-Tg Abs in SLE patients than in the control group. Although different methods of testing for TAbs in different studies and differences in iodine intake between different areas might explain some of the discrepancy ${ }^{(31)}$.

We aimed to assess the association between the prevalence of thyroid autoantibodies among patients with systemic rheumatic diseases with or without clinical thyroid disorders and its relation to disease activity and functional impairment. We found no statistically significant difference between SLE patients with positive \& negative thyroid Abs as regard SLEDAI score and SLICC/ACR damage index. No statistically significant difference was found between RA patients with positive \& negative thyroid Abs as regard DAS 28 score and HAQ score. And, no statistically significant difference in SSc patients with positive \& negative thyroid Abs as regard Rodnan modified index and Medsger index. This agrees with Posselt et al. ${ }^{(16)}$, who found that there was no statistically significant difference as regard SLEDAI and SLICC/ ACR between SLE patients with positive \& negative thyroid Abs, no statistically significant difference between RA patients as regard DAS 28 score or HAQ score with positive \& negative thyroid Abs, and no statistically significant difference as regard Rodnan modified index and Medsger index in SSc group with positive $\&$ negative thyroid Abs. Our findings were confirmed by Tekaya et al $^{\left({ }^{(32)} \text {, who found }\right.}$ that there were no significant differences in the DAS-28 between the RA patients with and without thyroid abnormalities. On the contrary, Koszarny et al. ${ }^{(33)}$, described thyroid autoantibodies as being more common in RA patients with high DAS-28 and the mean of DAS-28 was significantly higher in the TPO positive patients. Also, Joshi et al. ${ }^{(34)}$ found that RA patients with hypothyroidism had higher DAS28-ESR and significant correlations were observed between TSH levels and ESR as well as DAS28-ESR. In contrast, Przygodzka and Filipowicz-Sosnowska ${ }^{(25)}$ found that RA patients with thyroid disorders had a lower disease activity assessed using the DAS-28 than RA patients without thyroid disorders.

\section{CONCLUSION}

It could be concluded that the prevalence of thyroid autoantibodies; anti-thyroglobulin ( $\mathrm{Tg}$ $\mathrm{Ab}$ ) and anti-thyroid peroxidase (TPO $\mathrm{Ab}$ ) and thyroid disorders in SLE and SSc patients are higher than RA patients with and without thyroid disorders. No link could be established between the presence of thyroid autoantibodies and the results from any of the instruments used to measure inflammatory activity and functional impairment in these cases of rheumatic diseases.

\section{REFERENCES}

1. Eschler DC, Hasham A, Tomer Y (2011): The etiology of autoimmune thyroid diseases. Clinical Reviews in Allergy and Immunology, 41 (2):190197.

2. Shin JI, Kim MJ, Lee JS (2009): Graves' disease, rheumatoid arthritis, and anti-tumor necrosis factoralpha therapy. The Journal of Rheumatology, 36(2):449-450.

3. Franco JS, Amaya-Amaya J, Molano-González N et al. (2015): Autoimmune thyroid disease in Colombian patients with systemic lupus erythematosus. Clin Endocrinol (Oxf), 83:943-50.

4. Feldt-Rasmussen $U$ (2015): Increased risk of thyroid autoimmunity in rheumatoid arthritis. Endocrine, 50(1):4-5.

5. McInnes IB, Schett G (2011): The pathogenesis of rheumatoid Arthritis. N Engl J Med., 365:22052219.

6. Schwartzman-Morris J, Putterman C (2012): Gender Differences in the Pathogenesis and Outcome of Lupus and of Lupus Nephritis. Clin Dev Immunol., 2012:1-9.

7. Van Den Hoogen $\mathrm{F}$, Khanna D, Fransen $\mathrm{J}$ et al. (2013): 2013 classification criteria for systemic sclerosis: an American College of Rheumatology/European League against Rheumatism collaborative initiative. Arthritis Rheum., 65:2737-2747.

8. Aringer M, Costenbader K, Daikh D et al. (2019): 2019 European League Against Rheumatism/American College of Rheumatology Classification Criteria for Systemic Lupus Erythematosus. Arthritis \& Rheumatology, 71(9):1400-1412. 
9. Aletaha D, Neogi T, Silman AJ et al. (2010): 2010 Rheumatoid arthritis classification criteria: An American College of Rheumatology/European League Against Rheumatism collaborative initiative. Arthritis Rheum., 62:2569-2581.

10. Bombardier C, Gladman DD, Urowitz MB et al. (1992): Derivation of the SLEDAI. A disease activity index for lupus patients. The committee on prognosis studies in SLE. Arthritis and Rheumatology, 35(6):630-640.

11. Gladman DD, Goldsmith CH, Urowitz MB et al. (2000): The Systemic Lupus International Collaborating Clinics/American College of Rheumatology (SLICC/ACR) Damage Index for Systemic Lupus Erythematosus International Comparison. J Rheumatol., 27(2):373-6.

12. Salaffi F, Peroni M, Ferraccioli GF (2000): Discriminating ability of composite indices for measuring disease activity in rheumatoid arthritis: a comparison of the Chronic Arthritis Systemic Index, Disease Activity Score and Thompson's articular index. Rheumatology (Oxford), 39(1):90-6.

13. Ferraz MB, Oliveira LM, Araujo PM et al. (1990): Crosscultural reliability of the physical ability dimension of the health assessment questionnaire. J Rheumatol., 17(6):813-7.

14. Clements P, Lachenbruch P, Siebold J et al. (1995): Inter and intraobserver variability of total skin thickness score (modified Rodnan TSS) in systemic sclerosis. J Rheumatol., 22(7):1281-5.

15. Medsger TA, Silman AJ, Steen VD et al. (1999): A disease severity scale for systemic sclerosis: development and testing. J Rheumatol., 26(10):2159-67.

16. Posselt RT, Coelho VN, Pigozzo DC et al. (2017): Prevalence of thyroid autoantibodies in patients with systematic autoimmune rheumatic diseases. Crosssectional study. Sao Paulo Med J., 135:535-540.

17. Shahin AA, Abdoh S, Abdelrazik M (2002): Prolactin and thyroid hormones in patients with systemic sclerosis: correlations with disease manifestations and activity. Z Rheumatol., 61:7039.

18. Porkodi R, Ramesh S, Mahesh A et al. (2004): Thyroid dysfunction in systemic lupus erythematosus and rheumatoid arthritis. J Indian Rheumatol Assoc., 12:88-90.

19. Lin WY, Chang CL, Fu LS et al. (2015): Systemic lupus erythematosus and thyroid disease: a 10-year study. J Microbiol Immunol Infect., 48:676-83.

20. Appenzeller S, Pallone AT, Natalin RA et al. (2009): Prevalence of thyroid dysfunction in systemic lupus erythematosus. J Clin Rheumatol., 15(3):117-9.
21. El-Hadidi KT, El-Wakd MM, Mansour AM et al. (2014): Thyroid dysfunction and anti-thyroid antibodies in Egyptian patients with systemic lupus erythematosus: Correlation with clinical musculoskeletal manifestations. The Egyptian Rheumatologist, 36:173-178.

22. El-Sherif WT, El Gendi SS, Ashmawy MM et al. (2004): Thyroid disorders and autoantibodies in systemic lupus erythematosus and rheumatoid arthritis patients. Egypt J Immunol. 11(2):81-90.

23. Watad A, Mahroum N, Whitby A et al. (2016): Hypothyroidism among SLE patients: case-control study. Autoimmun Rev., 15:484-6.

24. Mader R, Mishail S, Adawi M et al. (2007): Thyroid dysfunction in patients with systemic lupus erythematosus (SLE): relation to disease activity. Clin Rheumatol., 26:1891-4.

25. Przygodzka M, Filipowicz-Sosnowska A (2009): Prevalence of thyroid diseases and antithyroid antibodies in women with rheumatoid arthritis. Pol Arch Med Wewn., 119:39-43.

26. Pan XF, Gu JQ, Shan ZY (2015): Increased risk of thyroid autoimmunity in rheumatoid arthritis: a systematic review and meta-analysis. Endocrine, 50(1):79-86.

27. Kumar K, Kole AK, Karmakar PS et al. (2012): The spectrum of thyroid disorders in systemic lupus erythematosus. Rheumatol Int., 32(1):73-8.

28. Pyne D, Isenberg DA (2002): Autoimmune thyroid disease in systemic lupus erythematosus. Ann Rheum Dis., 61:70-2.

29. Innocencio RM, Romaldini JH, Ward LS (2003): High prevalence of thyroid autoantibodies in systemic sclerosis and rheumatoid arthritis but not in the antiphospholipid syndrome. Clin Rheumatol., 22(6):494

30. Chan AT, Al-Saffar Z, Bucknall RC (2001): Thyroid disease in systemic lupus erythematosus and rheumatoid arthritis. Rheumatol., 40:353-4.

31. Chen C, Hu H, Chen Y et al. (2018): Iodized salt intake and its association with urinary iodine, thyroid peroxide antibodies, and thyroglobulin antibodies among urban Chinese. Thyroid, 27(12):1566-73.

32. Tekaya R, Tekaya AB, Sahli H et al. (2016): Relationship between autoimmune thyroid disorders and RA. JAMPS., 7(1):1-6.

33. Koszarny A, Majdan M, Suszek D, et al. (2013): Relationship between rheumatoid arthritis activity and antithyroid antibodies. Pol Arch Med Wewn., 123(78):394-400.

34. Joshi P, Agarwal A, Vyas S et al. (2017): Prevalence of hypothyroidism in rheumatoid arthritis and its correlation with disease activity. Trop Doct., 47(1):6-10. 